Article

\title{
The Recovery of Valuable Metals from Ocean Polymetallic Nodules Using Solid-State Metalized Reduction Technology
}

\author{
Feng Zhao ${ }^{1,2, *}$, , Xunxiong Jiang ${ }^{1,2, *}$, Shengdong Wang ${ }^{1,2}$, Linyong Feng ${ }^{1,2}$ and Da $\mathrm{Li}^{1,2}$ \\ 1 BGRIMM Technology Group, Beijing General Research Institute of Mining and Metallurgy, Beijing 102600, \\ China; 11wsd@sina.com (S.W.); fly2712@sina.com (L.F.); lida7858535@163.com (D.L.) \\ 2 National Engineering Technology Research Center for Comprehensive Utilization of Metal Mineral \\ Resources, Beijing 102600, China \\ * Correspondence: zhaofeng1315@163.com (F.Z.); xunxiong@163.com (X.J.)
}

Received: 19 November 2019; Accepted: 23 December 2019; Published: 25 December 2019

\begin{abstract}
Ocean polymetallic nodules are oxide ores rich in $\mathrm{Ni}, \mathrm{Co}, \mathrm{Cu}$, and $\mathrm{Mn}$, which are valuable metals found in deep-sea mineral resources. Such non-ferrous metals do not exist in isolation, and producing concentrates using conventional mineral separation techniques is challenging without pre-treatment. We propose an effective, environmentally-friendly recovery technology combined with solid-state metalized reduction treatment and magnetic separation to recycle these metals from ocean polymetallic nodules. We conducted single-factor tests to investigate the effects of additives, anthracite dosage, duration, and reduction temperature on metal recovery and to obtain optimal operating parameters. We found that valuable metals in ocean polymetallic nodules may be selectively reduced to a metallic state. Only a fraction of $\mathrm{Mn}$ was reduced to metal. The reduced metals were recovered to concentrates using magnetic separation. More than $80 \%$ of these metals were concentrated to magnetic concentrates with mass ratios of $10-15 \%$. The recovery rates of $\mathrm{Ni}, \mathrm{Co}, \mathrm{Cu}, \mathrm{Mn}$, and $\mathrm{Fe}$ in concentrates were optimum at $86.48 \%, 86.74 \%, 83.91 \%, 5.63 \%$, and $91.46 \%$, respectively, when using $\mathrm{CaF}_{2} 4 \%$, anthracite $7 \%, \mathrm{SiO}_{2}$ dosage $5 \%$, and $\mathrm{FeS} 6 \%$ at $1100{ }^{\circ} \mathrm{C}$ for $2.5 \mathrm{~h}$. This approach to non-ferrous metal extraction using conventional hydrometallurgical processes could be a step toward practical industrial-scale techniques for the recovery of metals from polymetallic nodules.
\end{abstract}

Keywords: ocean polymetallic nodules; solid-state metalized reduction; magnetic separation; alloy particles

\section{Introduction}

Due to rapid economic growth and technological advances, greater attention has been paid to the exploration and investigation of deep-sea resources. This is driven by an increasing need for alternative sources of metals, and much research has focused alternative extraction methods [1].

Polymetallic nodules are the earliest and longest studied deep-sea solid minerals, abundant on the soft sediment surface of the abyssal plains, trenches, valleys, undersea volcanoes, and islands at depths of approximately 4000-6000 m [2-5]. Besides containing Fe and Mn, polymetallic nodules are comprised of other non-ferrous metals, such as $\mathrm{Ni}, \mathrm{Co}$, and $\mathrm{Cu}$ with a total content of approximately $3 \%$ of these three metals. The crystallization degree of polymetallic nodules is poor, existing as semi-crystalline, crypto-crystalline, or amorphous forms. Fe and $\mathrm{Mn}$ are the main constituent metallic elements of nodules, found in the form of $10-\AA$ phyllomanganate $\left(\delta-\mathrm{MnO}_{2}\right)$ and goethite, in which $\mathrm{Ni}, \mathrm{Co}$, and $\mathrm{Cu}$ are irregularly distributed [5-7]. Valuable non-ferrous metals do not exist as isolated minerals; thus, polymetallic nodules cannot be treated using conventional mineral separation techniques, such 
as flotation or magnetic separation, to concentrate non-ferrous metals without pretreatment [8-10]. The valuable non-ferrous metal concentrates improve the economics of metal recovery in polymetallic nodules by reducing operating costs and the necessary material consumption [11].

There are two categories of known metallurgical technologies for processing polymetallic nodules: hydrometallurgy and pyrometallurgy. Hydrometallurgy mainly utilizes inorganic acid and ammonia solutions to dissolve targeted elements from ores using various reductants. These include normal-pressure acid leaching, high-temperature and high-pressure sulfuric acid leaching, and cuprous ion ammonia leaching processes [12-16]. Pyrometallurgy is conducted under high-temperature reducing conditions to process nodules via roasting or smelting, such as reduction roasting, chloridizing roasting, sulfatizing roasting, and reduction melting processes [17-20]. Owing to the distinct structure of polymetallic nodules, it is necessary to break down the highly oxidized $\mathrm{MnO}_{2}$ and $\mathrm{FeO}(\mathrm{OH})$ phase to reclaim the other metals in the nodules, as iron and manganese oxide phases can be dissociated only under reducing conditions $[5,6,11,21]$. Most metallurgy processes for polymetallic nodules require a pre-reduction of the oxide phases to release the locked elements. However, each process has its own advantages and limitations. The normal-pressure acid leaching process is simple and provides a higher metal-leaching rate. However, it has poor selectivity, high acid consumption, and a complex solution purification process, and it generates a large amount of waste-water and residue. Although the high-pressure sulfuric acid leaching process can improve leaching selectivity, it requires advanced equipment, which demands a large investment. The ammonia leaching process provides decent leaching selectivity, enables recycling of the leaching reagent, and retains the manganese in the ammonia leaching residue. However, this process is time-intensive, has low cobalt recovery, and requires the treatment of ammonia nitrogen waste-water. Reduction smelting is a typical pyrometallurgical process that treats polymetallic nodules, but a high recovery rate of valuable metals can only be achieved with high energy consumption. In addition, the alloy obtained is difficult to break, which does not lend itself well to subsequent wet processing.

Based on these reviews, the Beijing General Research Institute of Mining and Metallurgy proposed a new reduction process, namely coal-based metallization of polymetallic nodules [22]. In this process, the solid-state metalized reduction of polymetallic nodules was carried out using coal as the reductant at low temperature. Multi-metals selective reduction and magnetic separation of valuable metals were successful using the different reduction temperatures of the various metal oxides. Solid-state metalized reduction had the advantage of being a short process with convenient subsequent treating of the powdery alloy. There was also an examination of the effect of the parameters controlling the alloy migration aggregation and the recovery of valuable metals contained in the polymetallic nodules.

\section{Material and Methods}

\subsection{Raw Material}

The polymetallic nodules used in the present study were collected from the China Ocean Sample Repository (COSR), Qingdao, China. Prior to the experiment, nodules were crushed and finely ground. The ore $(80 \%$ particle size $<75 \mu \mathrm{m})$ was dried at $100^{\circ} \mathrm{C}$ for subsequent experiments. A representative polymetallic nodule sample was obtained through the coning and quartering method. Anthracite $(80 \%$ particle size $<74 \mu \mathrm{m})$ was used as a reducing agent. The chemical composition of anthracite is presented in Table 1. The other reagents used, $\mathrm{CaF}_{2}, \mathrm{SiO}_{2}$ and $\mathrm{FeS}$, were of analytical grade.

Table 1. Chemical analysis of the reductant (air dried).

\begin{tabular}{ccccc}
\hline Properties & Fixed Carbon & Volatile Matter & Ash & Moisture \\
\hline Content (wt. \%) & 75.35 & 7.55 & 14.88 & 2.22 \\
\hline
\end{tabular}




\subsection{Apparatus and Procedure}

Firstly, the polymetallic nodules, anthracite, and additives were mixed in a laboratory mixing tank at a specific experimental ratio, and 10-15\% water was added to create pellets under $30 \mathrm{MPa}$. The raw pellets were dried and preheated in corundum crucibles to ensure a certain compressive strength, drop strength, and anti-explosion temperature.

In the reduction roasting tests, the preheated pellets were heated for a period of time in a SX16-18-16/38 accurate temperature control muffle furnace using corundum crucibles with supporting lids to ensure sealing. All test conditions are listed in Table 2. When the roasting process was complete, the reduced sample was slowly cooled in the furnace with no additional gas introduced to minimize re-oxidation of the reduced valuable metals. The cooled reduction product was ground with a planetary ball mill to $100 \%$ passing $75 \mu \mathrm{m}$. The finely ground product was mixed with a certain amount of water to form a slurry. The slurry was wet magnetic separated using a DTCXG-ZN50 magnetic tube at $140 \mathrm{mT}$ to obtain the valuable metal concentrates and rich manganese tailings. The concentrates and tailings were dried at $333 \mathrm{~K}\left(60{ }^{\circ} \mathrm{C}\right)$ for $8 \mathrm{~h} \mathrm{[23].}$

Table 2. Process parameters of the experiments.

\begin{tabular}{cccccccc}
\hline \multirow{2}{*}{ Studied Parameters } & \multirow{2}{*}{ Range } & \multicolumn{5}{c}{ Fixed Parameters } \\
\cline { 3 - 8 } & & $\mathbf{C}$ & $\mathbf{A}$ & $\mathbf{t}$ & $\mathbf{S}$ & $\mathbf{F}$ & $\mathbf{T}$ \\
\hline $\mathrm{CaF}_{2}$ dosage/wt. \% & $0,1,2,3,4,5$ & - & 7 & 3 & 5 & 0 & 1100 \\
Anthracite dosage/wt. \% & $5,7,8,9,10$ & 4 & - & 3 & 5 & 0 & 1100 \\
Reaction duration/h & $1,1.5,2,2.5,3,4$ & 4 & 7 & - & 5 & 0 & 1100 \\
$\mathrm{SiO}$ dosage/wt. \% & $0,2,4,5,6$ & 4 & 7 & 2.5 & - & 0 & 1100 \\
$\mathrm{FeS}$ dosage/wt. \% & $0,4,6,8,10$ & 4 & 7 & 2.5 & 5 & - & 1100 \\
Reaction temperature $/{ }^{\circ} \mathrm{C}$ & $1000,1050,1100,1150$ & 4 & 7 & 2.5 & 5 & 6 & - \\
\hline
\end{tabular}

$\mathrm{C}: \mathrm{CaF}_{2}$ dosage (\%); A: anthracite dosage (\%); t: reaction duration (h); $\mathrm{S}: \mathrm{SiO}_{2}$ dosage (\%); $\mathrm{F}$ : $\mathrm{FeS}$ dosage (\%); $\mathrm{T}$ : reaction temperature $\left({ }^{\circ} \mathrm{C}\right)$.

\subsection{Analysis}

The potassium dichromate titration method was used for the high-grade manganese and iron test [24]. The other chemical compositions of the concentrates and the tailings were analyzed using an inductively coupled plasma optical emission spectrometer (ICP-OES, Agilent 700, Agilent technology (China) Co. LTD., Beijing, China). The semi-quantitative mineralogical analyses of the ocean polymetallic nodules were conducted using X-ray diffraction (XRD) (Rigaku, Tokyo, Japan) with $\mathrm{Cu}-\mathrm{K} \alpha \mathrm{X}$-radiation, and the scan rate was set at $20^{\circ} 2 \theta / \mathrm{min}$. Scanning electron microscopy (SEM; KYKY-2800, KYKY TECHNOLOGY CO., LTD., Beijing, China) and energy dispersive spectroscopy (EDS; EDAX, Genesis, EDAX Inc, Beijing, China) were performed on the concentrates and the tailings. EDS was performed on selected points to obtain the local composition of the sample.

\section{Results}

\subsection{Characterization of Ocean Polymetallic Nodules}

The chemical composition of ocean polymetallic nodules is presented in Table 3.

Table 3. Main chemical composition of ocean polymetallic nodules/wt. \%.

\begin{tabular}{cccccccccc}
\hline $\mathbf{N i}$ & $\mathbf{C o}$ & $\mathrm{Cu}$ & $\mathrm{Fe}$ & $\mathrm{Mn}$ & $\mathrm{SiO}_{2}$ & $\mathrm{Al}_{2} \mathbf{O}_{3}$ & $\mathrm{CaO}$ & $\mathbf{M g O}$ & $\mathrm{Na}_{2} \mathbf{O}$ \\
\hline 1.04 & 0.17 & 0.87 & 5.80 & 23.84 & 14.12 & 4.99 & 2.57 & 3.12 & 2.21 \\
\hline
\end{tabular}

Figure 1 illustrates the XRD pattern, which suggests that $10-\AA$ phyllomanganate, quartz, and feldspar were the major constituent minerals of the polymetallic nodules. Observation of the crystal 
structure of the nodules indicated that $\mathrm{Ni}, \mathrm{Cu}$, and $\mathrm{Co}$ are bound to the $\left(\mathrm{MnO}_{6}\right)$ octahedra of Mn-oxide [11]. No isolated Ni-, Co-, or Cu-bearing crystalline structures were observed in the XRD pattern.

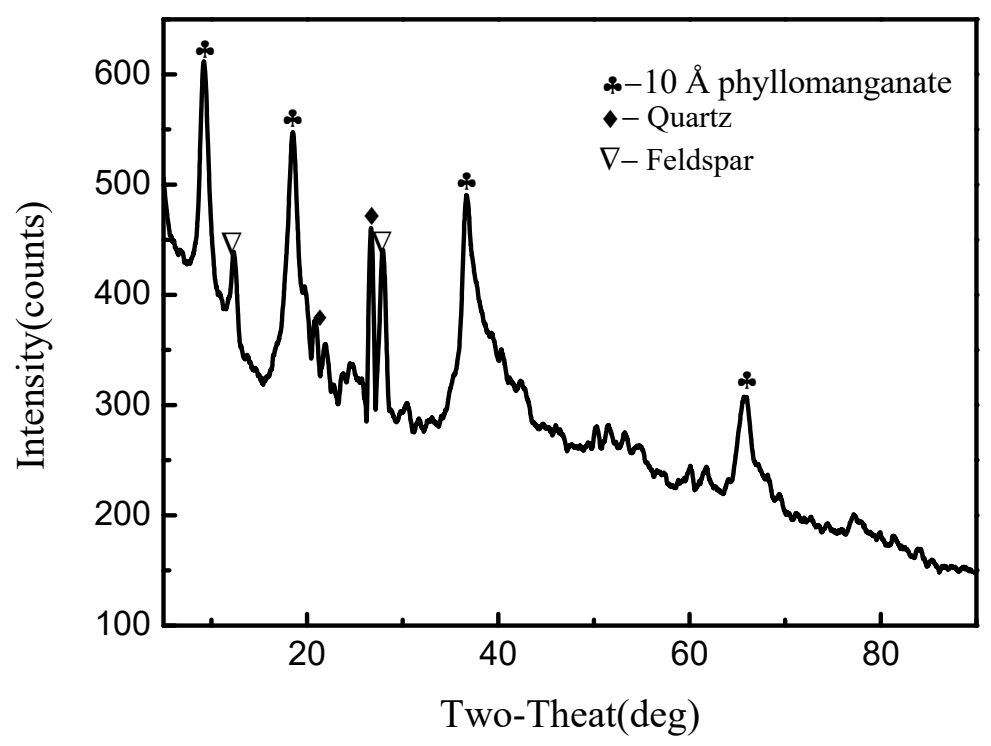

Figure 1. X-ray diffraction (XRD) pattern of polymetallic nodules.

\subsection{Thermodynamic Analysis}

A selective reduction process is based on the difference in reduction temperatures of several main metal oxides. Selective reduction of polymetallic oxides can be achieved by controlling the temperature interval. The oxides of $\mathrm{Ni}, \mathrm{Co}, \mathrm{Cu}$, and Fe were reduced to form metallic states, and $\mathrm{MnO}_{2}$ was reduced to $\mathrm{MnO}$.

The reaction formula of metal oxides reduced by carbon is as follows:

$$
\begin{gathered}
\mathrm{MeO}+\mathrm{C}=\mathrm{Me}+\mathrm{CO} \\
2 \mathrm{MeO}+\mathrm{C}=2 \mathrm{Me}+\mathrm{CO}_{2}
\end{gathered}
$$

where $\mathrm{Me}$ is $\mathrm{Ni}, \mathrm{Co}, \mathrm{Cu}, \mathrm{Fe}, \mathrm{Mn}$, etc.

The standard Gibbs free energy changes of the main Equations (3)-(12) in the solid-state metalized reduction process were calculated using HSC 6.0 software.

$$
\begin{gathered}
\mathrm{NiO}(\mathrm{s})+\mathrm{C}(\mathrm{s})=\mathrm{Ni}(\mathrm{s})+\mathrm{CO}(\mathrm{g}) \\
\Delta G^{\ominus}=[121,094-171.67 T] \mathrm{J} \cdot \mathrm{mol}^{-1} \quad T_{0}=705.38 \mathrm{~K} \\
\mathrm{CoO}(\mathrm{s})+\mathrm{C}(\mathrm{s})=\mathrm{Co}(\mathrm{s})+\mathrm{CO}(\mathrm{g}) \\
\Delta G^{\ominus}=[131,084-164.27 T] \mathrm{J} \cdot \mathrm{mol}^{-1} \quad T_{0}=797.96 \mathrm{~K} \\
\mathrm{CuO}(\mathrm{s})+\mathrm{C}(\mathrm{s})=\mathrm{Cu}(\mathrm{s})+\mathrm{CO}(\mathrm{g}) \\
\Delta G^{\ominus}=[37,829-170.96 T] \mathrm{J} \cdot \mathrm{mol}^{-1} \quad T_{0}=221.27 \mathrm{~K} \\
3 \mathrm{Fe}_{2} \mathrm{O}_{3}(\mathrm{~s})+\mathrm{C}(\mathrm{s})=2 \mathrm{Fe}_{3} \mathrm{O}_{4}(\mathrm{~s})+\mathrm{CO}(\mathrm{g}) \\
\Delta G^{\ominus}=[237,700-222.00 T] \mathrm{J} \cdot \mathrm{mol}^{-1} \quad T_{0}=1070.72 \mathrm{~K} \\
\mathrm{Fe}_{3} \mathrm{O}_{4}(\mathrm{~s})+\mathrm{C}(\mathrm{s})=3 \mathrm{FeO}(\mathrm{s})+\mathrm{CO}(\mathrm{g}) \\
\Delta G^{\ominus}=[262,350-179.70 T] \mathrm{J} \cdot \mathrm{mol}^{-1} \quad T_{0}=1459.93 \mathrm{~K}
\end{gathered}
$$




$$
\begin{gathered}
\mathrm{FeO}(\mathrm{s})+\mathrm{C}(\mathrm{s})=\mathrm{Fe}(\mathrm{s})+\mathrm{CO}(\mathrm{g}) \\
\Delta G^{\Theta}=\left[147,763-150.06 \mathrm{~J} \cdot \mathrm{mol}^{-1} \quad T_{0}=984.68 \mathrm{~K}\right. \\
\mathrm{MnO}_{2}(\mathrm{~s})+\mathrm{C}(\mathrm{s})=\mathrm{MnO}(\mathrm{s})+\mathrm{CO}(\mathrm{g}) \\
\Delta G^{\ominus}=[24,698.86-199.00 T] \mathrm{J} \cdot \mathrm{mol}^{-1} \quad T_{0}=124.11 \mathrm{~K} \\
\mathrm{MnO}(\mathrm{s})+\mathrm{C}(\mathrm{s})=\mathrm{Mn}^{(\mathrm{s})}+\mathrm{CO}(\mathrm{g}) \\
\Delta G^{\Theta}=[574,332-339.21 T] \mathrm{J} \cdot \mathrm{mol}^{-1} \quad T_{0}=1693.16 \mathrm{~K} \\
3 \mathrm{MnO}(\mathrm{s})+4 \mathrm{C}(\mathrm{s})=\mathrm{Mn}_{3} \mathrm{C}(\mathrm{s})+3 \mathrm{CO}(\mathrm{g}) \\
\Delta G^{\Theta}=[569,960-304.25 T] \mathrm{J} \cdot \mathrm{mol}^{-1} \quad T_{0}=1498.77 \mathrm{~K} \\
\Delta G^{\ominus}=[287,715.03-162.01 T] \mathrm{J} \cdot \mathrm{mol}^{-1} \quad T_{0}=1775.91 \mathrm{~K}
\end{gathered}
$$

where $T_{0}$ is the initial reaction temperature.

The standard Gibbs free energy changes $\left(\Delta G^{\theta}\right)$ are plotted as a function of temperature in Figure 2 for Equations (3)-(12), demonstrating that all reactions were notably temperature-dependent.

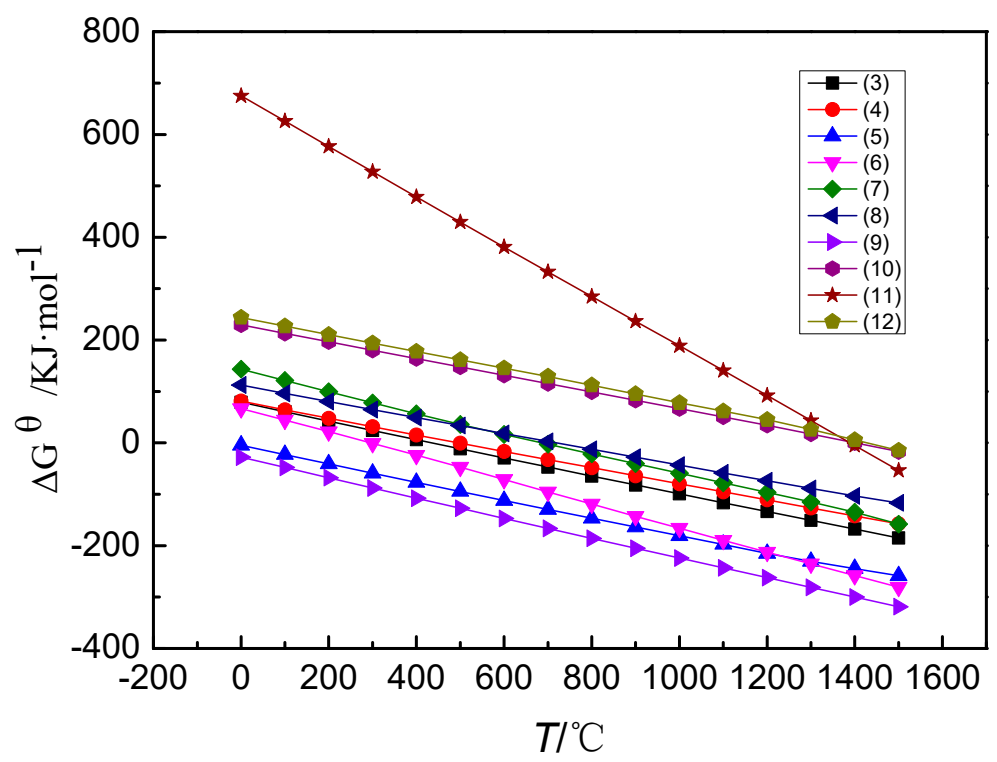

Figure 2. Temperature effects on the standard Gibbs free energy changes for Equations (3)-(12).

$T_{0}$ reflects the initial temperature at which these oxides were reduced by carbon. $\mathrm{MnO}_{2}$ reduction had the lowest initial temperature and priority. The reduction of the four oxides $\mathrm{NiO}, \mathrm{CoO}, \mathrm{CuO}$, and $\mathrm{Fe}_{2} \mathrm{O}_{3}$ was much easier than that of $\mathrm{MnO}$. Among them, $\mathrm{Fe}_{2} \mathrm{O}_{3}$, the most difficult to be reduced, started with a reduction temperature of $1070.72 \mathrm{~K}$, much lower than that for $\mathrm{MnO}(1693.16 \mathrm{~K})$. This provides a temperature range for selective reduction.

If the amount of reducing agent is too large, a considerable amount of unreacted carbon remains after the reaction. When the temperature is above $1498.77 \mathrm{~K}$, there was a reaction of Equation (11) generating manganese carbide. When the temperature rose above $1775.91 \mathrm{~K}$, there was a reaction of Equation (12) leading to part of the manganese reduction into the metal. Therefore, temperature and dosage of carbon are very important, and great consideration must be given to the technological conditions at play. Through thermodynamic analysis, the solid metallization reduction of polymetallic nodules was feasible. 


\subsection{Solid-State Metalized Reduction}

\subsubsection{Effect of $\mathrm{CaF}_{2}$ Addition}

Figure 3 illustrates the effects of $\mathrm{CaF}_{2}$ addition on the contents and recoveries of these valuable metals. The recoveries of $\mathrm{Cu}, \mathrm{Co}, \mathrm{Ni}$, and $\mathrm{Fe}$ were observed to increase constantly with $\mathrm{CaF}_{2}$ dosing from $0 \%$ to $4 \%$. However, metal recoveries plateaued after $4 \% \mathrm{CaF}_{2}$ dosage, while the recovery of $\mathrm{Mn}$ remained low. The grades of $\mathrm{Cu}, \mathrm{Co}, \mathrm{Ni}$, and $\mathrm{Fe}$ in the magnetic concentrates displayed an overall upward trend in $\mathrm{CaF}_{2}$ dosing from $0 \%$ to $4 \%$, with maximum values obtained at $4 \% \mathrm{CaF}_{2}$ dosage. $\mathrm{Mn}$ grade exhibited an overall downward trend with increasing $\mathrm{CaF}_{2}$ addition.
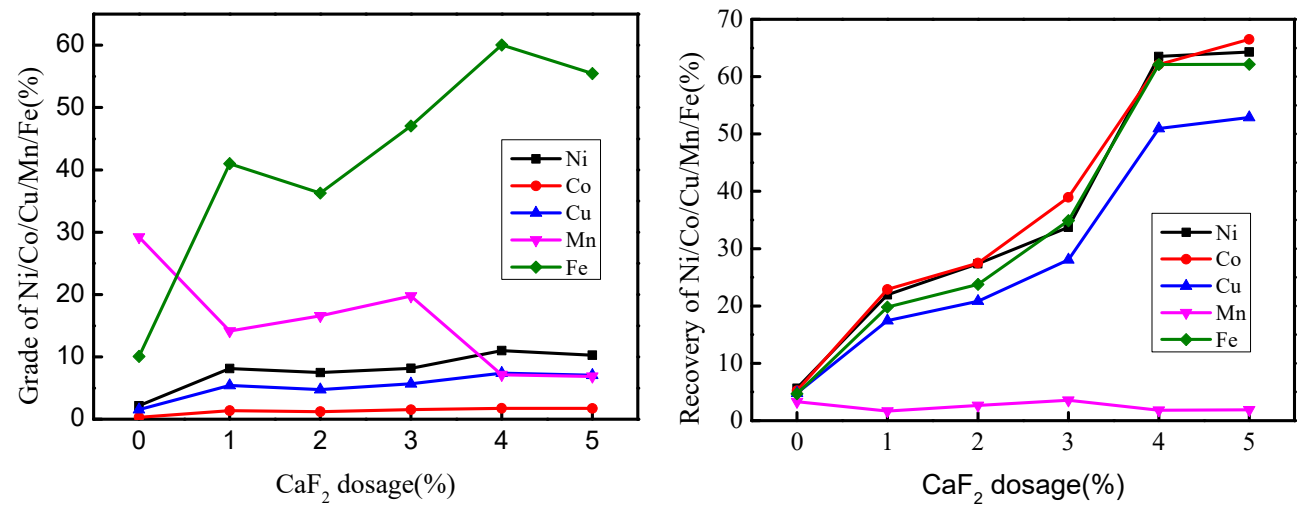

Figure 3. Effect of $\mathrm{CaF}_{2}$ addition on the concentration of valuable metals.

Figure 4 presents the SEM image of reduction calcines $\left(\mathrm{CaF}_{2}\right.$ dosage $0 \%$ and $\left.4 \%\right)$, where the generation of many light alloy particles and irregular distribution in the gray matrix was observed. The grain size of the alloy in calcines at $0 \% \mathrm{CaF}_{2}$ dosage was very small $(<10 \mu \mathrm{m})$. However, the grain size of the alloy in calcines at $4 \% \mathrm{CaF}_{2}$ dosage had clearly increased, ranging from dozens to hundreds of microns.
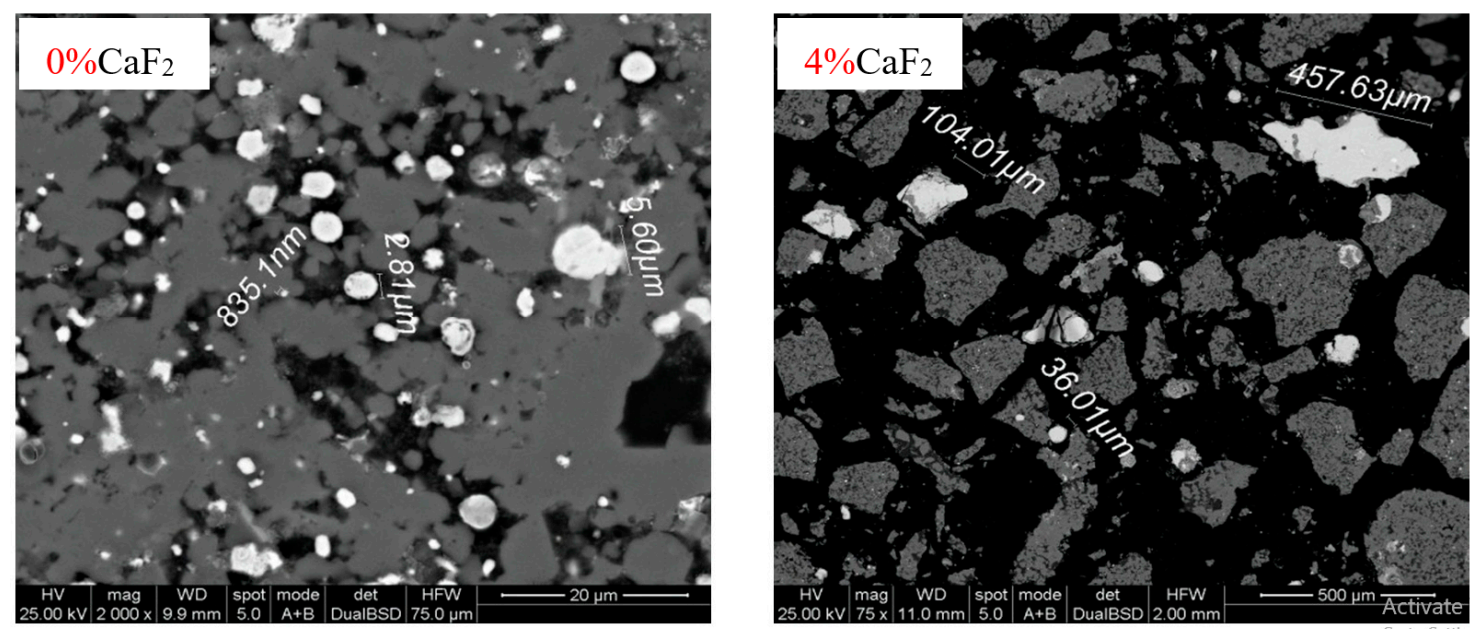

Figure 4. Scanning electron microscopy (SEM) image of the reduction calcines in $0 \%$ and $4 \% \mathrm{CaF}_{2}$.

Furthermore, we found that $\mathrm{CaF}_{2}$ decreased the surface tension of alloy particles and the mineral melting point, and promoted the migration and aggregation of metalized valuable metals. Hence, adding $\mathrm{CaF}_{2}$ can substantially increase the recovery of valuable metals. Moreover, $\mathrm{CaF}_{2}$ can promote the generation of iron-based alloys and improve the aggregation of alloy particles. As such, the use of $\mathrm{CaF}_{2}$ improves the beneficiation of valuable metals by magnetic separation, particularly at $4 \%$ $\mathrm{CaF}_{2}$ dosage. 


\subsubsection{Effect of Anthracite Dosage}

Figure 5 presents the analysis of the effect of anthracite dosage on grade and recovery. The metal recoveries improved with increased anthracite dosage and reached the maximum values. This demonstrates that the dosage of less than $7 \%$ has a substantial influence on valuable metal recovery. The grade of $\mathrm{Ni}, \mathrm{Co}, \mathrm{Cu}$, and Fe increased constantly, while the grade of $\mathrm{Mn}$ decreased with increasing anthracite dosage. After $7 \%$ dosage, we observed that increasing the anthracite did not improve metal recovery. Furthermore, beyond 9\% dosage, the grade of Mn increased in the magnetic concentrate with an increase in anthracite dosage. To some extent, excessive coal was needed to improve the reducing atmosphere. However, when the anthracite dosage was greater than $9 \%$, superfluous anthracite lead to increased $\mathrm{Mn}$ and $\mathrm{MnC}$, and generated greater amounts of ash in the magnetic concentrates. This was found to decrease the grade of $\mathrm{Cu}, \mathrm{Co}, \mathrm{Ni}$, and Fe. Thus, an anthracite dosage of $7 \%$ is optimal for recovering valuable metals.
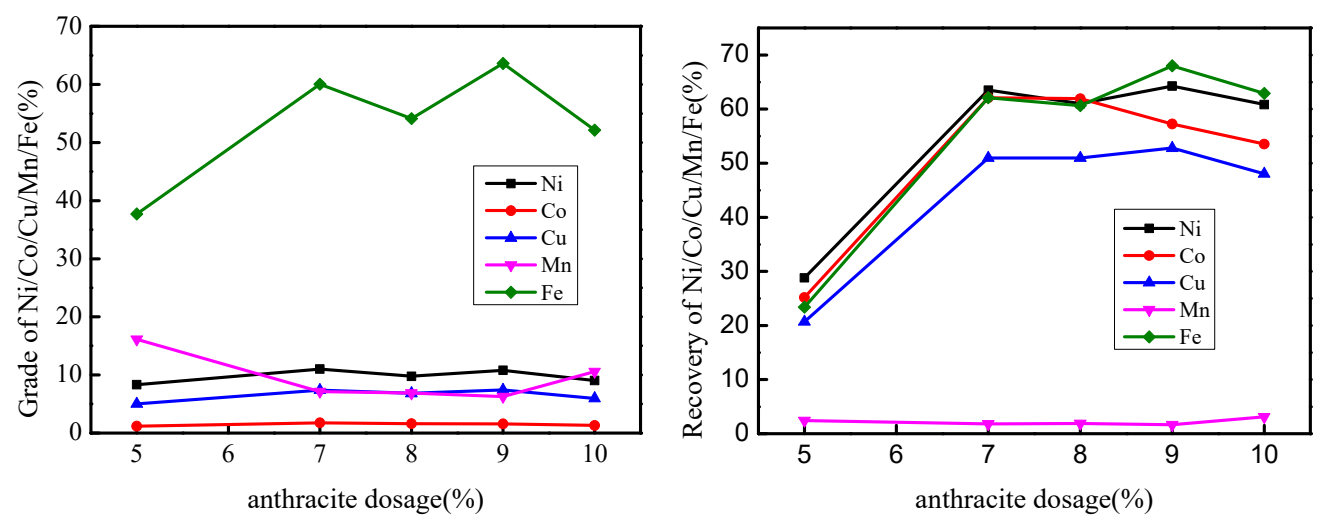

Figure 5. Effect of anthracite dosage on the concentration of valuable metals.

Figure 6 shows the SEM image of reduction calcines (anthracite dosages of 5\%, 7\%, and 9\%). We observed that the reaction of metalized reduction was insufficient with an anthracite dosage of $5 \%$, and there were no typical round alloy particles in calcines. However, there were some large typical round alloy particles in calcines with an anthracite dosage of $7 \%$ and $9 \%$. Additionally, the grain size of the two sets was very similar.

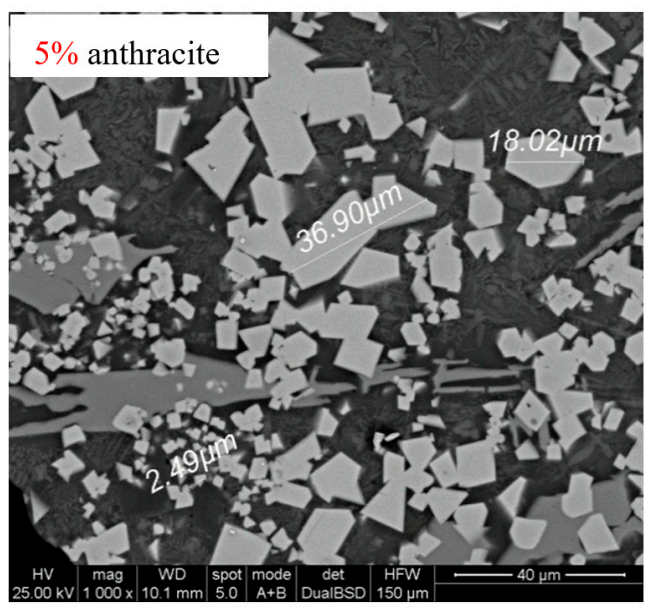

Figure 6. Cont. 

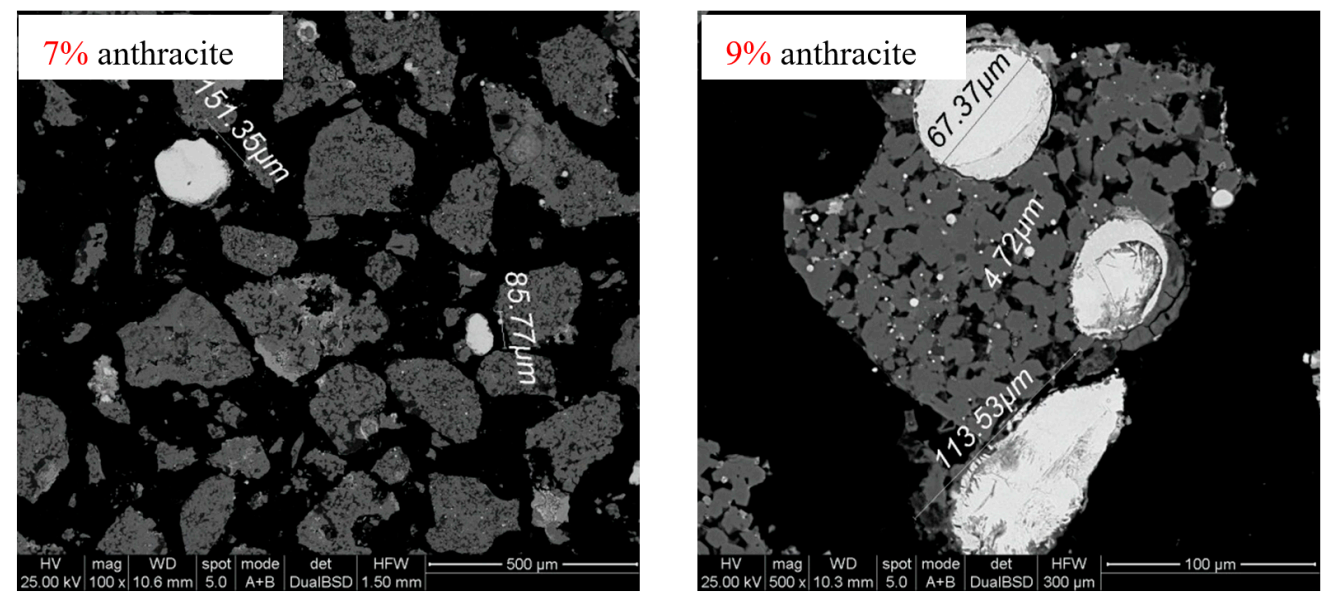

Figure 6. SEM image of the reduction calcines in 5\%, 7\%, and $9 \%$ anthracite.

\subsubsection{Effect of Reaction Duration}

Figure 7 illustrates the impact of reaction duration on metal recovery. The results indicate that the recovery of $\mathrm{Cu}, \mathrm{Co}$, and $\mathrm{Ni}$ gradually increased from a roasting period of $0.5 \mathrm{~h}$ up to $2.5 \mathrm{~h}$. However, metal recovery was unaffected by reaction times beyond $2.5 \mathrm{~h}$. The recovery of $\mathrm{Mn}$ initially increased slightly, then decreased before $2.5 \mathrm{~h}$, and increased beyond $2.5 \mathrm{~h}$. The grades of $\mathrm{Ni}, \mathrm{Co}, \mathrm{Cu}$, and $\mathrm{Mn}$ increased constantly before $1.5 \mathrm{~h}$ and then plateaued. Furthermore, the grade of Fe increased before $2.5 \mathrm{~h}$ and decreased beyond $2.5 \mathrm{~h}$. This suggests that short reaction duration $(<2.5 \mathrm{~h})$ may lead to an inadequate response in the metalized reduction process. Moreover, the low metal recovery suggests that the generated alloy particles were not recovered well by magnetic separation, as there was insufficient time to grow up and aggregate adequately. The decrease in recovery and grades beyond $3 \mathrm{~h}$ may be due to the tiny alloy particles involved in the generated silicate of tailings. As such, $2.5 \mathrm{~h}$ was deemed sufficient for good recovery and grades.
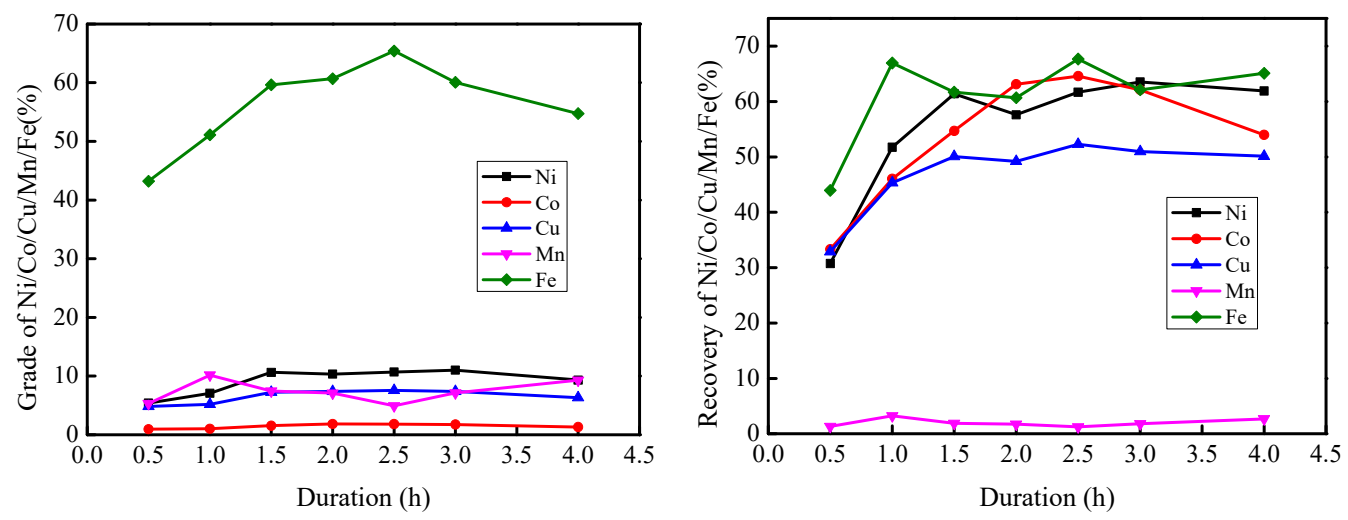

Figure 7. Effect of reaction duration on the concentration of valuable metals.

\subsubsection{Effect of $\mathrm{SiO}_{2}$ Dosage}

The effect of $\mathrm{SiO}_{2}$ dosage was analyzed, and Figure 8 illustrates the grade and recovery trends. The recovery and grades of $\mathrm{Cu}, \mathrm{Co}, \mathrm{Ni}$, and Fe were observed to increase constantly with $\mathrm{SiO}_{2}$ dosing between $0 \%$ and $5 \%$. However, metal recovery and grades plateaued beyond $5 \% \mathrm{SiO}_{2}$ dosing. In contrast, the grade and recovery of $\mathrm{Mn}$ decreased with an increase in $\mathrm{SiO}_{2}$ dosage. This indicates that a dosage of $5 \% \mathrm{SiO}_{2}$ is optimal to achieve the required grade and recovery of the metals. 

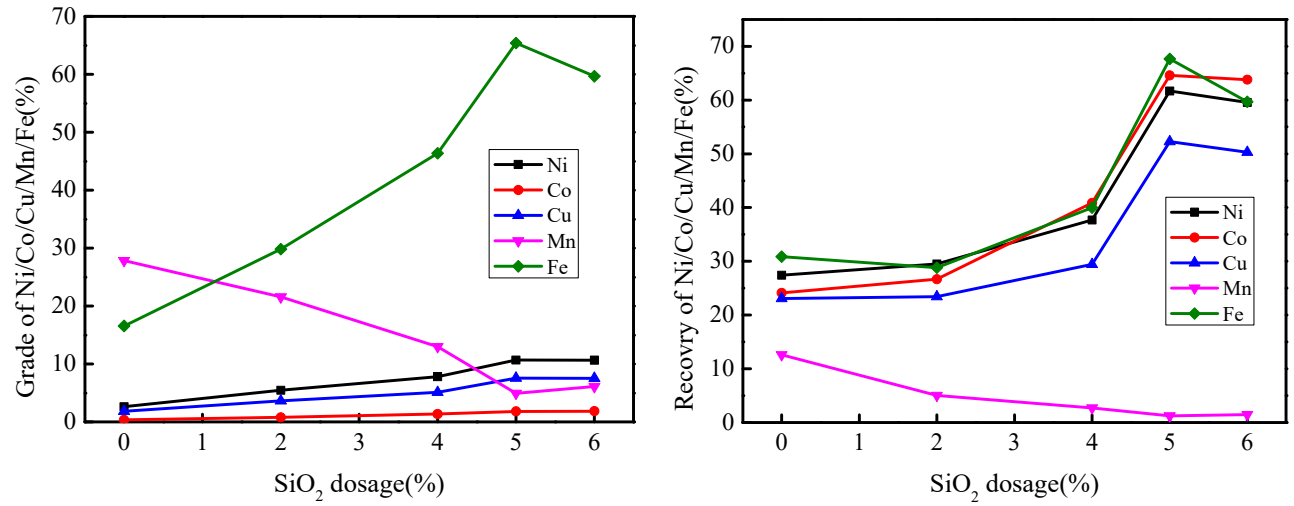

Figure 8. Effect of $\mathrm{SiO}_{2}$ dosage on the concentration of valuable metals.

Figure 9 presents the SEM image of reduction calcines $\left(\mathrm{SiO}_{2}\right.$ dosage $0 \%$ and $\left.5 \%\right)$. The grain size of the alloy in calcines at $0 \% \mathrm{SiO}_{2}$ dosage was very small $(<10 \mu \mathrm{m})$. However, the grain size of the alloy in calcines with $5 \% \mathrm{SiO}_{2}$ dosage increased considerably, ranging from dozens to hundreds of microns. This suggests that $\mathrm{SiO}_{2}$ can strengthen the aggregation of alloy particles and improve the fluidity of slags. Thus, the slag-making material improves the beneficiation of valuable metals by a metalized reduction magnetic separation process.
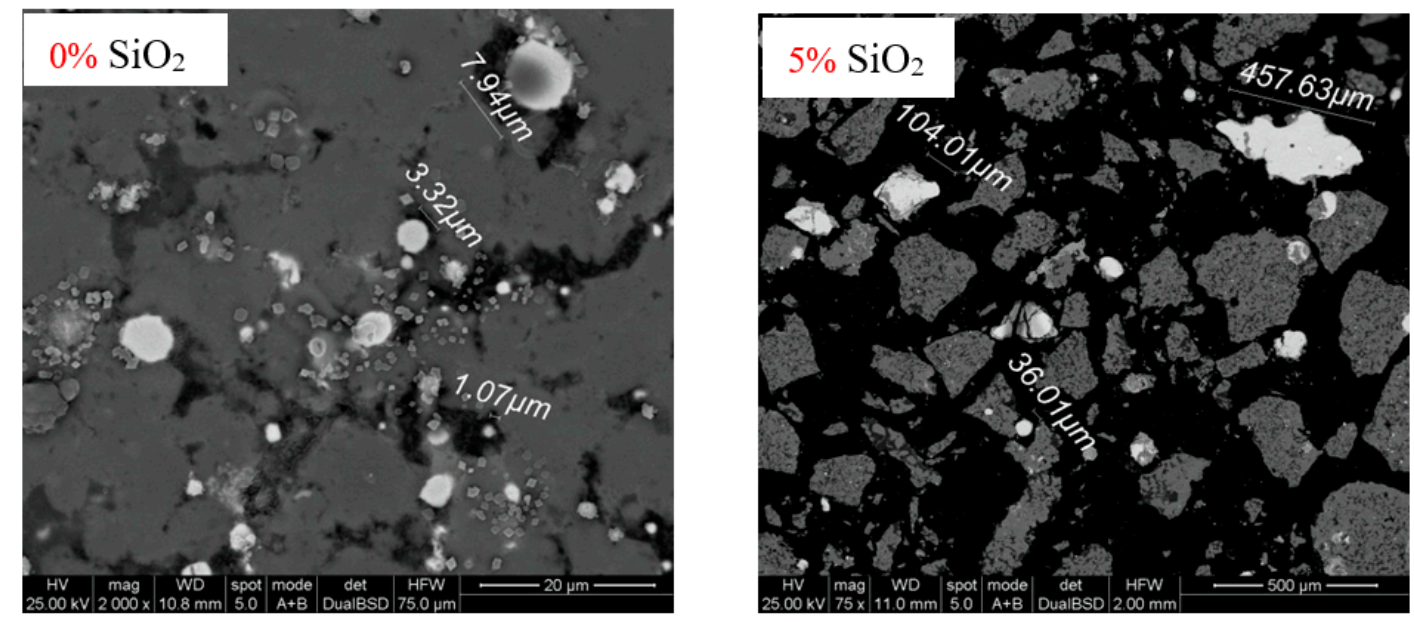

Figure 9. SEM image of the reduction calcines in $0 \%$ and $5 \% \mathrm{SiO}_{2}$.

\subsubsection{Effect of FeS Dosage}

The results depicted in Figure 10 show that the grades of $\mathrm{Cu}, \mathrm{Co}$, and Ni decreased constantly with an increase in FeS dosage, while the grade and recovery of Mn increased. The grade of Fe was observed to increase up to $4 \%$ dosage and then decreased. The recovery of $\mathrm{Cu}, \mathrm{Co}, \mathrm{Ni}$, and $\mathrm{Fe}$ increased with $\mathrm{FeS}$ dosing between $0 \%$ and $6 \%$. However, metal recoveries plateaued beyond $6 \% \mathrm{FeS}$ dosage. Co recovery decreased after $6 \%$ dosage and had a comparable recovery level to $\mathrm{Cu}$. Based on the grades and recovery of the valuable metals in the concentrates, an FeS dosage of $6 \%$ ( $2.18 \%$ containing sulfur) was found to be optimal. 

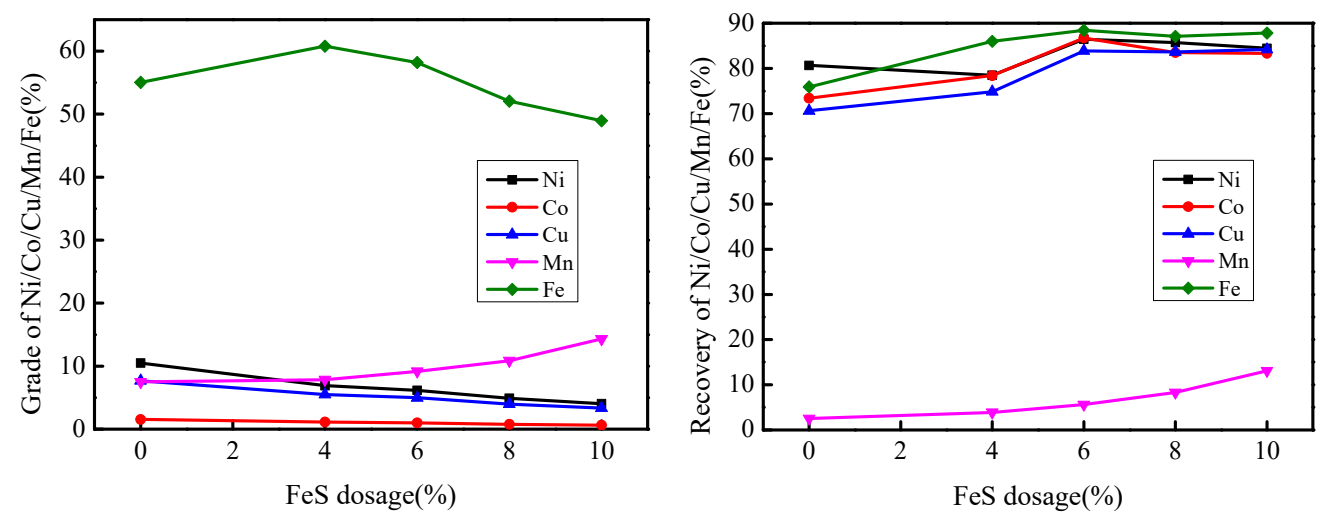

Figure 10. Effect of FeS dosage on the concentration of valuable metals.

\subsubsection{Effect of Reaction Temperature}

Figure 11 depicts the effect of reaction temperature on recovery and grade, suggesting that an increase in temperature from 1000 to $1100{ }^{\circ} \mathrm{C}$ led to a sharp increase in the recovery of $\mathrm{Cu}, \mathrm{Co}, \mathrm{Ni}$, and Fe. However, increasing the temperature beyond $1100^{\circ} \mathrm{C}$ led to a slow increase in recovery. The grades of $\mathrm{Cu}, \mathrm{Co}, \mathrm{Ni}, \mathrm{Fe}$, and $\mathrm{Mn}$ in the magnetic concentrates increased constantly with reaction temperature. In contrast, the recovery and grade of $\mathrm{Mn}$ decreased with an increase in reaction temperature. This indicates that the reaction temperature is highly influential on metal recovery and grades. Furthermore, the migration and aggregation behavior of iron-based alloy particles substantially improved with increased reaction temperature. In terms of kinetics, a higher temperature resulted in a faster metallization reaction rate. However, if the reaction temperature was greater than $1100{ }^{\circ} \mathrm{C}$, it led to a sintering adhesion phenomenon of the crucible. This was found to seriously affect the follow-up process operations. As such, $1100^{\circ} \mathrm{C}$ was found to be the most appropriate reaction temperature.
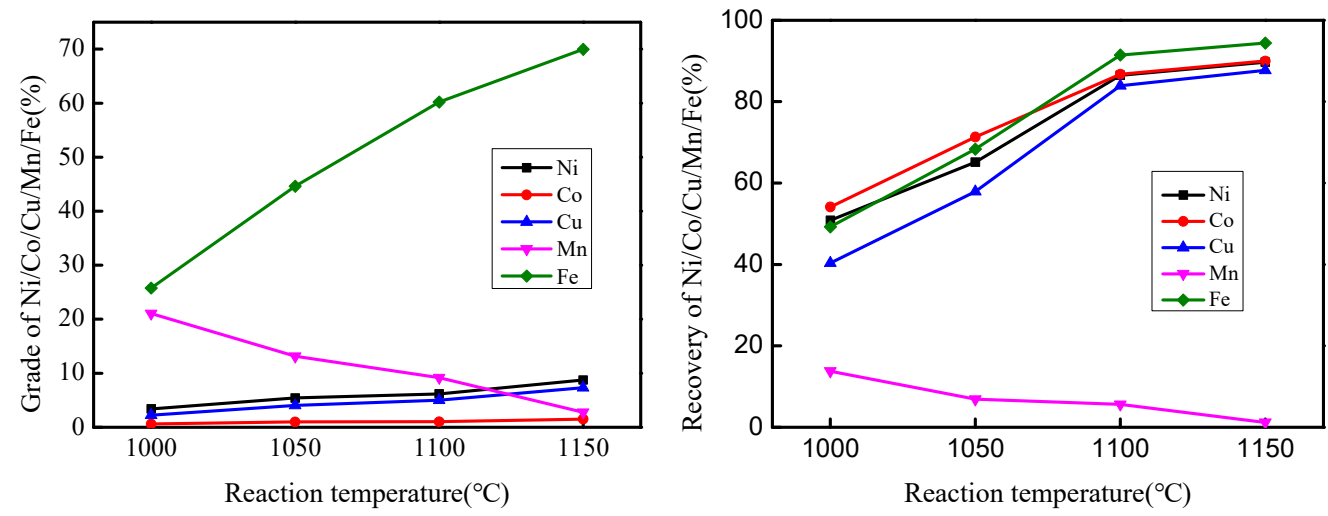

Figure 11. Effect of reaction temperature on the concentration of valuable metals.

The SEM image of reduction calcines (reaction temperatures of $1000{ }^{\circ} \mathrm{C}, 1050{ }^{\circ} \mathrm{C}, 1100{ }^{\circ} \mathrm{C}$, and $1150^{\circ} \mathrm{C}$ ) are shown in Figure 12. The observations suggested that the grain size of the alloy in calcines increased dramatically with an increase in reaction temperature. Most of the alloy particles aggregated as larger particles from the initial fine scattered particles when the reaction temperature reached $1150{ }^{\circ} \mathrm{C}$. The obtained sizes were almost greater than $100 \mu \mathrm{m}$. 

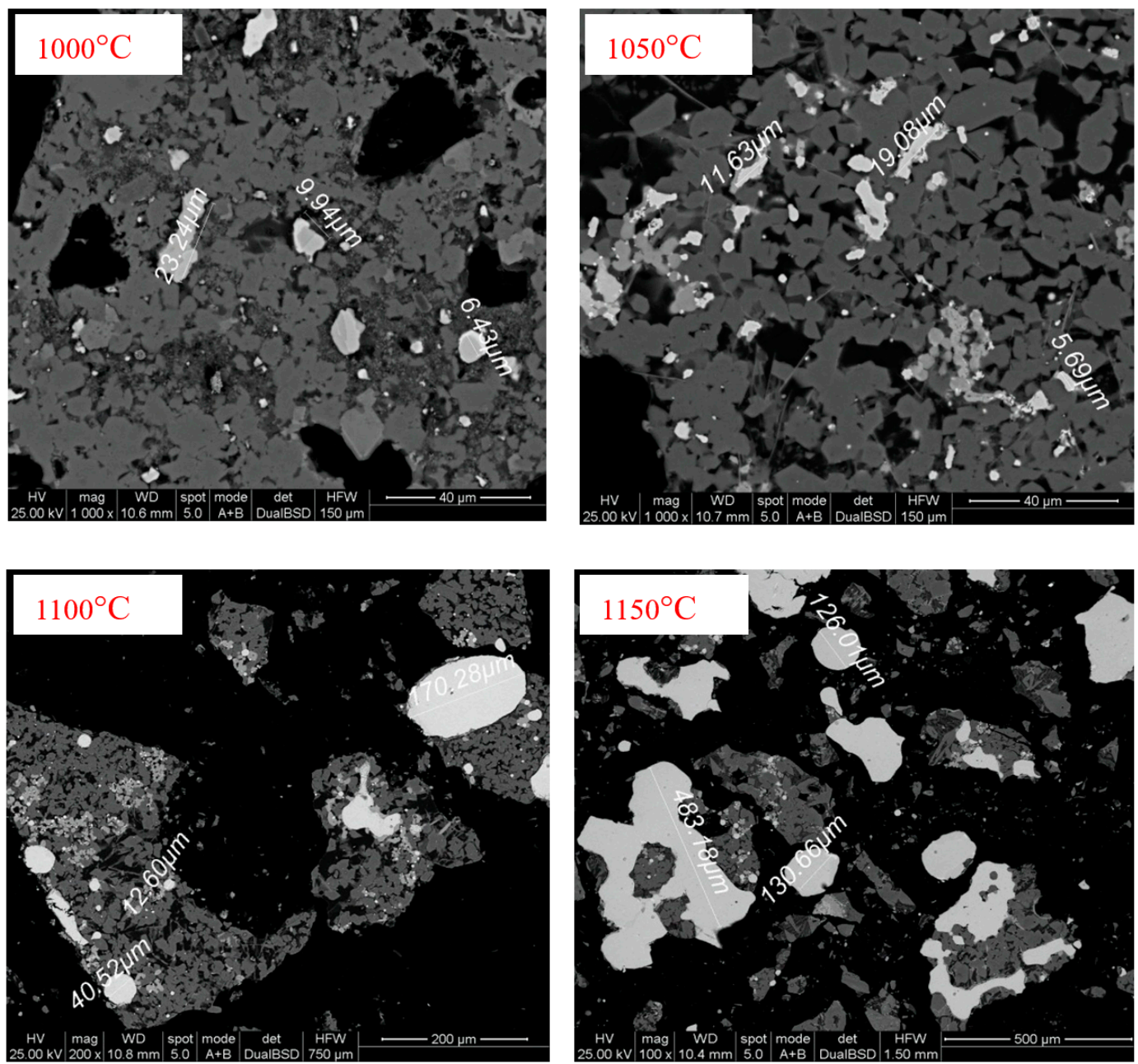

Figure 12. SEM image of the reduction calcines at $1000^{\circ} \mathrm{C}, 1050^{\circ} \mathrm{C}, 1100{ }^{\circ} \mathrm{C}$, and $1150{ }^{\circ} \mathrm{C}$.

\section{Discussion}

The action mechanism of the additives used in the test were as follows:

1. Function of $\mathrm{CaF}_{2}$ : metal oxides can only be reduced in situ, and valuable metals cannot migrate and aggregate at the experimental temperature range. Fine particles have a large surface area and surface energy, thereby forming an unstable thermodynamic system. Thus, the alloy particles may spontaneously aggregate with nearby particles to decrease the free enthalpy of the system and form agglomerated particles [25]. These agglomerated particles hinder the separation of metalized valuable metals from non-magnetic material. $\mathrm{CaF}_{2}$ can decrease the surface tension of alloy particles and the mineral melting point, and promote the migration and aggregation of metalized valuable metals as the alloy particle size grows [23] (see Figure 4). Hence, adding $\mathrm{CaF}_{2}$ can significantly increase the recovery of valuable metals (Figure 3).

2. Function of $\mathrm{SiO}_{2}$ : the composition and alkalinity of slag are the main factors that affect its melting point and viscosity. Therefore, a certain amount of $\mathrm{SiO}_{2}$ should be added to adjust the alkalinity when necessary according to the composition of ores in the fire treatment process. This can inhibit the reduction of Mn (Figure 8), reduce the viscosity of slag, improve the fluidity of slag, and promote the separation of slag and alloy [26].

3. Function of FeS: sulfur elements of FeS and valuable metals form some of the metal sulfides in the process of metallization reduction. These metal sulfides often bind alloy particles. As such, the reduction alloy particles are connected to the sulfide by birth, gathering themselves together. They promote the growth of alloy particles, and thus enhance the metal recovery of magnetic concentrate [7]. 
Figure 13 illustrates the SEM image and energy spectrum (four different color areas) of the reduction calcines under optimal conditions $\left(1100{ }^{\circ} \mathrm{C}, 2.5 \mathrm{~h}, \mathrm{CaF}_{2} 4 \%\right.$, anthracite $7 \%, \mathrm{SiO}_{2} 5 \%$, and FeS 6\%).
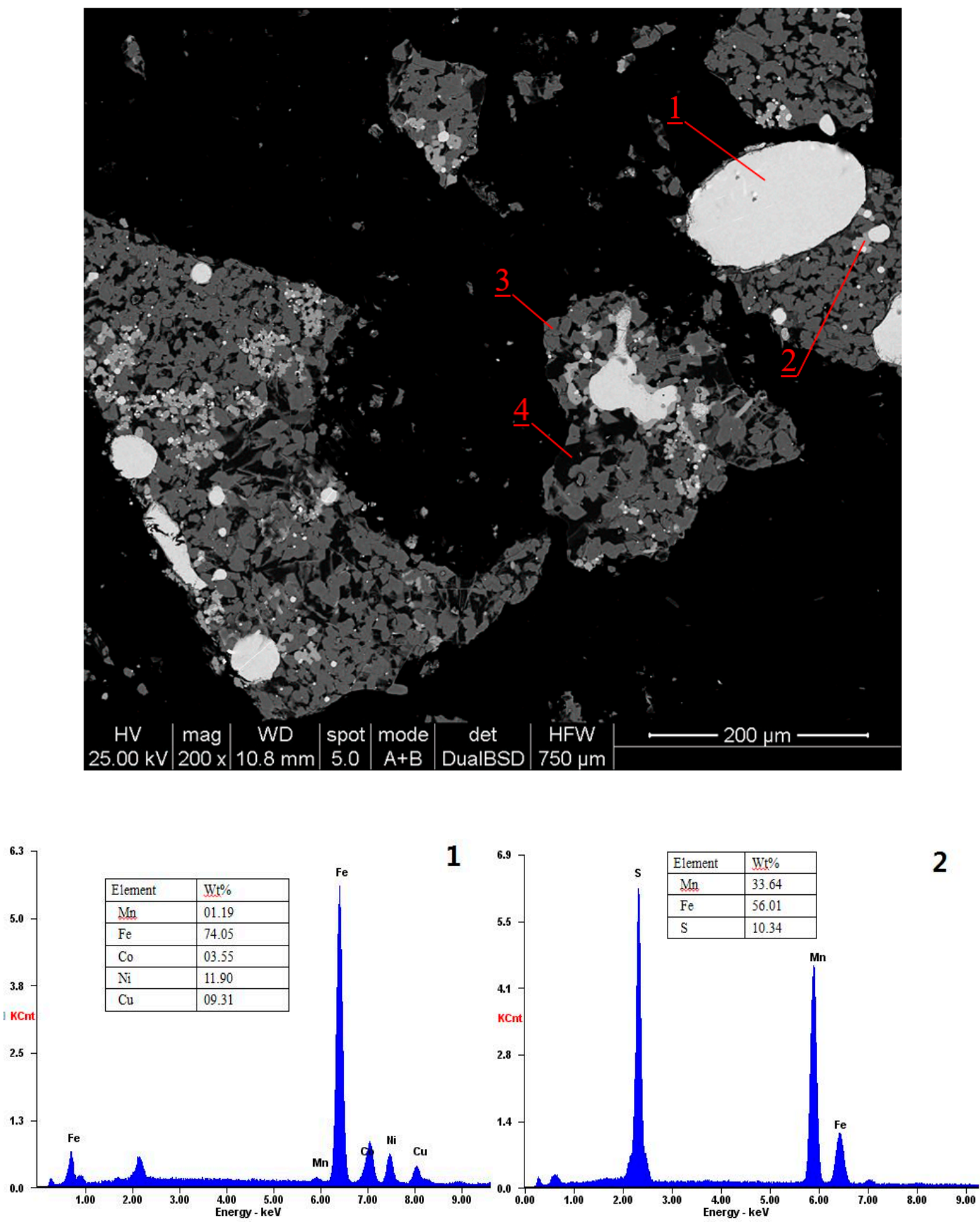

Figure 13. Cont. 

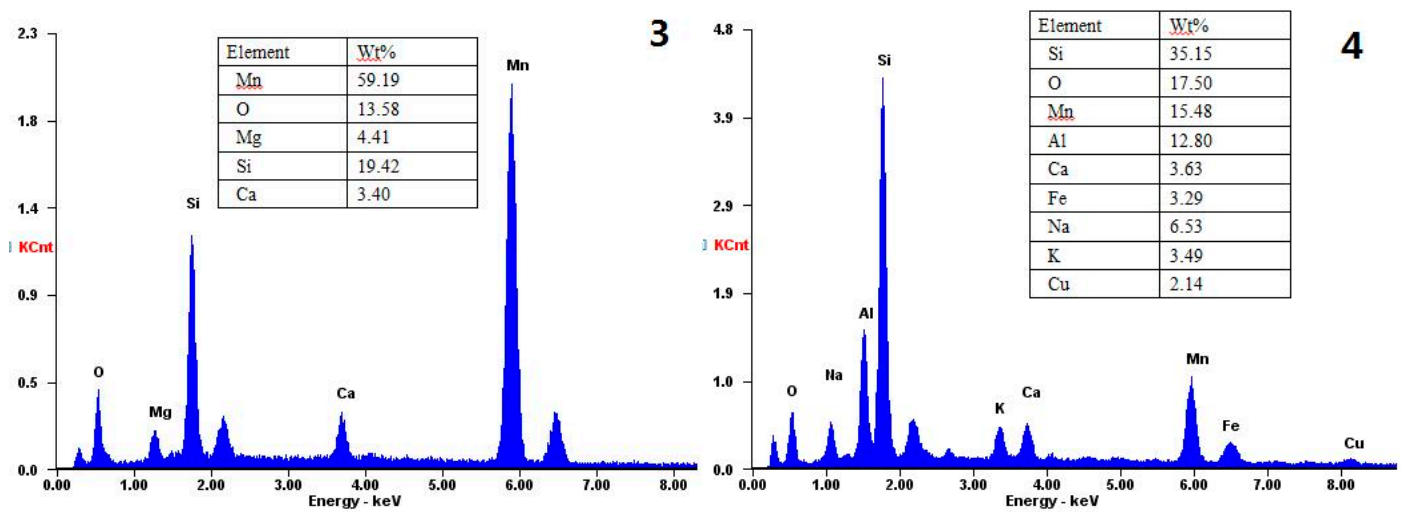

Figure 13. SEM image and energy spectrum of the reduction calcines at $1100{ }^{\circ} \mathrm{C}$.

The mineral composition of the four color areas is very different. The bright white point 1 is the alloy phase formed by $\mathrm{Fe}, \mathrm{Co}, \mathrm{Ni}$, and $\mathrm{Cu}$. The light gray point 2 is the ferro manganese sulfide phase, the dark gray point 3 is the manganese olivine phase, and the black point 4 is the glass phase.

Mineral liberation analysis (MLA) was used to analyze the alloy particles size in four groups of reduction calcines at different temperatures to obtain the distribution of alloy particles size (see Figure 14). A valuable analysis result was not obtained in this case, as the alloy particle size was very fine in calcine at $1000^{\circ} \mathrm{C}$, and the fine alloy particles were wrapped in slag phase.

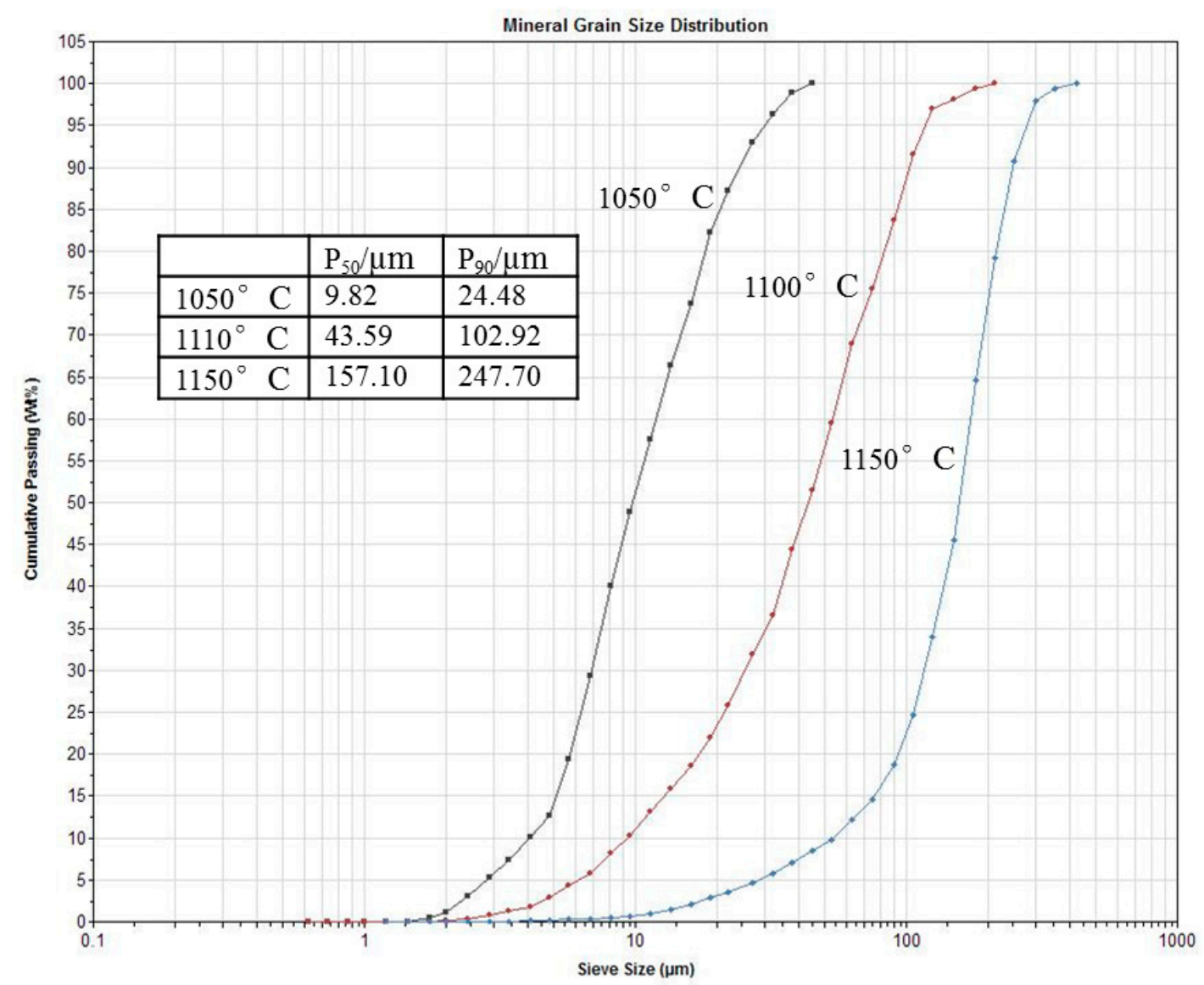

Figure 14. Alloy particles size distribution of the calcines at $1050^{\circ} \mathrm{C}, 1100{ }^{\circ} \mathrm{C}$, and $1150{ }^{\circ} \mathrm{C}$.

The results show that with the increase in temperature, the alloy particles size increases, and the distribution interval shifts to a larger size. 


\section{Conclusions}

This study carried out solid-state metalized reduction of polymetallic nodules using coal as the reductant at a lower temperature rather than reduction smelting for the first time. This process enabled the enrichment of the main valuable metals to approximately $10 \%$ concentrate. As non-ferrous metals do not exist in isolation, polymetallic nodules cannot be treated by conventional mineral separation techniques to produce non-ferrous metal concentrates without pretreatment. The production of concentrate is essential in the overall economics of recovering and refining valuable metals contained in polymetallic nodules.

Based on the findings of this study, the following conclusions may be drawn:

1. The polymetallic nodules typically consist of $\mathrm{Mn}$-rich low-Ni/Co/Cu oxide ore. The major constituent minerals of the ore were 10- $\AA$ phyllomanganate and silicates. The former was the main valuable metal-bearing mineral.

2. The single factor tests suggested that reaction temperature, reaction duration, $\mathrm{CaF}_{2}$, anthracite, $\mathrm{SiO}_{2}$, and $\mathrm{FeS}$ were the main influencing factors on the beneficiation of valuable metals and alloy grain size.

3. The valuable metals of ocean polymetallic nodules were selectively reduced to metallic state, and only a fraction of $\mathrm{Mn}$ was reduced to metal. The reduced valuable metals were recovered to concentrates using a magnetic separation process. More than $80 \%$ of the valuable metals $(\mathrm{Ni}, \mathrm{Co}, \mathrm{Cu}$, and $\mathrm{Fe}$ ) of ocean polymetallic nodules were concentrated to magnetic concentrates, with a mass ratio between $10 \%$ and $15 \%$.

4. The recovery of $\mathrm{Ni}, \mathrm{Co}, \mathrm{Cu}, \mathrm{Mn}$, and $\mathrm{Fe}$ in concentrates was $86.48 \%, 86.74 \%, 83.91 \%, 5.63 \%$, and $91.46 \%$, respectively. The optimal conditions for this were $1100{ }^{\circ} \mathrm{C}, 2.5 \mathrm{~h}, \mathrm{CaF}_{2} 4 \%$, anthracite $7 \%, \mathrm{SiO}_{2}$ dosage $5 \%$, FeS 6\%.

Author Contributions: Conceptualization, F.Z. and X.J.; methodology, F.Z. and X.J.; validation, S.W., L.F. and D.L.; formal analysis, L.F.; investigation, F.Z., X.J. and D.L.; resources, S.W. and D.L.; data curation, F.Z. and X.J.; writing—original draft preparation, F.Z.; writing—review and editing, F.Z., L.F. and X.J.; visualization, F.Z.; supervision, X.J.; project administration, X.J. All authors have read and agreed to the published version of the manuscript.

Funding: This research was funded by the National Natural Science Foundation of China (No. 51704024) and China Ocean Mineral Resources Research and Development Association (JS-KTHT-2018-01).

Acknowledgments: The authors would like to thank the BGRIMM Institute of Analytical Chemistry for the chemical composition and mineralogical analyses.

Conflicts of Interest: The authors declare no conflict of interest.

\section{References}

1. Senanayake, G. Acid leaching of metals from deep-sea manganese nodules-A critical review of fundamentals and applications. Miner. Eng. 2011, 24, 1379-1396. [CrossRef]

2. Zhu, K.C.; Li, Z.S.; He, G.W. The East Pacific Ocean Polymetallic Nodules Mining, 1st ed.; Geological Publishing House: Beijing, China, 2001.

3. Xiao, L.J.; Fang, M.; Zhang, W.M. Advance and present state of the research in oceanic metalliferous nodule mining. Metal Mine 2000, 8, 11-14.

4. Liu, Y.G.; Yao, H.Q.; Yu, M.; Ren, J.B.; Yang, Y. International seabed mineral resources exploration and the research progress. Mar. Inf. 2014, 3, 10-16.

5. Kuhn, T.; Wegorzewski, A.; Rühlemann, C.; Vink, A. Composition, Formation, and Occurrence of Polymetallic Nodules. In Deep-Sea Mining: Resource Potential, Technical and Environmental Considerations; Sharma, R., Ed.; Springer International: Cham, Switzerland, 2017; pp. 23-46.

6. Wegorzewski, A.V.; Kuhn, T.; Dohrmann, R.; Wirth, R.; Grangeon, S. Mineralogical characterization of individual growth structures of $\mathrm{Mn}$-nodules with different $\mathrm{Ni}+\mathrm{Cu}$ content from the central Pacific Ocean. Am. Mineral. 2015, 100, 2497-2508. [CrossRef] 
7. Zhao, F.; Jiang, X.X. Effect of sulfur-bearing substance on metallic reduction of oceanic polymetallic nodules. Nonferrous Metals 2014, 1, 15-18.

8. Anna, V.W.; Thomas, K. The influence of suboxic diagenesis on the formation of manganese nodules in the Clarion Clipperton nodule belt of the Pacific Ocean. Mar. Geol. 2014, 1, 123-138.

9. Wang, J.X.; Wang, P.; Li, H.R. Fluidizing reduction roasting of ocean polymetallic nodule. J. Cent. South Univ. Technol. 2011, 42, 361-364. [CrossRef]

10. Feng, X.W.; Qian, J.C.; Zhang, P.Z. The study of phase change of 1nm manganite in polymetallic nodules and its main controlling factors. Acta Mineral. Sin. 2003, 23, 109-114.

11. Wegorzewski, A.V.; Köpcke, M.; Kuhn, T.; Sitnikova, M.A.; Wotruba, H. Thermal pretreatment of polymetallic nodules to create metal (Ni, Cu, Co)-rich individual particles for further processing. Minerals 2018, 8, 523. [CrossRef]

12. Anand, S.; Das, S.C.; Das, R.P.; Jena, P.K. Leaching of manganese nodules at elevated temperatures and pressures in presence of oxygen. Hydrometallurgy 1988, 20, 155-168. [CrossRef]

13. Mehta, K.D.; Das, C.; Pandey, B.D. Leaching of copper, nickel and cobalt from Indian Ocean manganese nodules by Aspergillus niger. Hydrometallurgy 2010, 105, 89-95. [CrossRef]

14. Parhi, P.K.; Park, K.H.; Nam, C.W.; Park, J.T.; Barik, S.P. Extraction of rare earth metals from deep sea nodule using $\mathrm{H}_{2} \mathrm{SO}_{4}$ solution. Int. J. Miner. Process. 2013, 119, 89-92. [CrossRef]

15. Parhi, P.K.; Park, K.H.; Nam, C.W.; Park, J.T. Liquid-liquid extraction and separation of total rare earth (RE) metals from polymetallic manganese nodule leaching solution. J. Rare Earths 2015, 33, 207. [CrossRef]

16. Barik, R.; Sanjay, K.; Mishra, B.K.; Mohapatra, M. Micellar mediated selective leaching of manganese nodule in high temperature sulfuric acid medium. Hydrometallurgy 2016, 165, 44-50. [CrossRef]

17. Yin, C.Q.; Jiang, X.X.; Zhou, B.Y.; Wu, X.J. Activating sulfuric acid leaching to extract valuable metals from ocean manganese nodules. Nonferrous Metals 1997, 1, 62-69.

18. Jiang, K.X.; Jiang, X.X.; Wang, S.D.; Fan, Y.Q.; Zhao, L.; Li, Z.Y. Reductive ammonia leaching of ocean polymetallic nodules. Nonferrous Metals 2005, 57, 54-57.

19. Sridhar, R.; Jones, W.E.; Warner, J.S. Extraction of copper, nickel and cobalt from sea nodules. JOM 1976, 28, 32-37. [CrossRef]

20. Zhu, D.Q.; Qiu, G.Z.; Jiang, T.; Xu, J.C. An innovative process for direct reduction of cold-bound pellets from iron concentrate with a coal-based rotary kiln. J. Cent. South Univ. Technol. 2000, 7, 68-71. [CrossRef]

21. Acharya, R.; Ghosh, M.K.; Anand, S.; Das, R.P. Leaching of metals from Indian Ocean nodules in $\mathrm{SO}_{2}-\mathrm{H}_{2} \mathrm{O}-\mathrm{H}_{2} \mathrm{SO}_{4}-\left(\mathrm{NH}_{4}\right)_{2} \mathrm{SO}_{4}$ medium. Hydrometallurgy 1999, 53, 169-175. [CrossRef]

22. Zhao, F.; Jiang, X.X. Magnetism of alloy particles from metallic reduction of polymetallic nodules. Nonferrous Metals Eng. 2015, 5, 32-35.

23. Ma, B.Z.; Xing, P.; Yang, W.J.; Wang, C.Y.; Chen, Y.Q.; Wang, H. Solid-state metalized reduction of magnesium-rich low-nickel oxide ores using coal as the reductant based on thermodynamic analysis. Metall. Mater. Trans. B 2017, 48, 2037-2046. [CrossRef]

24. Pig Iron Contententing Nickel-Determination of Iron Content-Dichromate Titration Method; Chinese Standard Press: Beijing, China, 2016.

25. Zarzycki, J.; Prassas, M.; Phalippou, J. Synthesis of glasses from gels: The problem of monolithic gels. J. Mater. Sci. 1982, 17, 33-71. [CrossRef]

26. Mao, Y.J.; Qu, S.G.; He, Z.Q.; Zhong, X. Smelting of ocean polymetallic nodules in DC arc furnace. Min. Metall. Eng. 1999, 19, 43-45.

(C) 2019 by the authors. Licensee MDPI, Basel, Switzerland. This article is an open access article distributed under the terms and conditions of the Creative Commons Attribution (CC BY) license (http://creativecommons.org/licenses/by/4.0/). 